\title{
Bond behavior between concrete and multi-directional CFRP
}

\section{laminates using the MF-EBR strengthening technique}

\author{
Mário Coelho ${ }^{1, a}$, Pedro Fernandes ${ }^{1, b}$, José Sena-Cruz ${ }^{1, c}$, Joaquim Barros ${ }^{1, d}$ \\ ${ }^{1}$ ISISE, University of Minho, School of Engineering, Department of Civil Engineering, \\ Azurém, 4800-058 Guimarães, Portugal \\ amcoelho@civil.uminho.pt, ${ }^{b}$ pfernandes@civil.uminho.pt, ${ }^{\text {jisena@civil.uminho.pt, }}$ \\ dbarros@civil.uminho.pt
}

Keywords: multi-directional CFRP laminates; pullout tests; bond behavior; MF-EBR strengthening technique.

\begin{abstract}
The strengthening technique based on the use of multi-directional laminates of CFRP simultaneously glued and fixed with anchors (MF-EBR) has been recently purposed. An experimental program composed of pullout tests was carried out in order to study the bond behavior between concrete and MF-EBR system. The diameter and number of anchors, the pre-stress level applied to the anchors, and the strengthening procedures were the main analyzed parameters. The present work describes the carried-out tests and presents and analyzes the most significant obtained results.
\end{abstract}

\section{Introduction}

The FRPs that are being used in the structural strengthening of concrete elements are practically limited to the unidirectional direction through the following techniques: (i) application of fabrics (in situ cured systems) or laminates glued externally on the surface of the element to strengthen (EBR - Externally Bonded Reinforcement); (ii) insertion of laminates (or rods) into slits opened on the concrete cover (NSM Near-Surface Mounted). In these two techniques the bond between the FRP and the element to be strengthened is usually assured by epoxy type adhesives. Consequently, the strengthening performance depends significantly of the superficial concrete resistance and, generally, the full mechanical capacity of the FRPs is not mobilized.

To avoid premature debonding failure of FRP reinforcement, some FRP-based alternative systems for structural strengthening have been proposed using either multi-directional laminates of glass and carbon fibers that are anchored to concrete elements [1], or multi-directional laminates of carbon fibers (MDL-CFRP) simultaneously glued and anchored to concrete [2]. The former strengthening technique is called the Mechanically Fastened Reinforcement FRP (MF-FRP), whereas the latter is named mechanically fastened and externally bonded reinforcement (MF-EBR).

The efficiency of NSM, EBR and MF-EBR techniques was recently compared by means of four-point bending tests with $\mathrm{RC}$ beams submitted to monotonic and fatigue 
Coelho, M.; Fernandes, P.; Melo, J.; Sena-Cruz, J.M.; Varum, H.; Barros, J.; Costa, A. (2011) "Seismic retrofit of RC beam-column joints using the MF-EBR strengthening technique." Advanced Materials Research.

loading [3]. When compared with the EBR strengthening technique, the MF-EBR has shown an important increase of carrying capacity (at about 40\%), deflection capacity at failure (at about 140\%).

This paper presents and discusses the results of the experimental program conducted to evaluate the bond behavior between multi-directional CFRP laminates and concrete prisms strengthened by the MF-EBR technique.

\section{Experimental Program}

The experimental program was composed by fourteen series, each one containing three specimens. In the context of the present work the main analyzed parameters were: the diameter and number of anchors, the pre-stress level applied to the anchors, and the strengthening procedure used. Code names given to the test series consist of alphanumeric characters (see Table 1). The first string indicates the diameter of the anchor (M8 and M10 for 8 and $10 \mathrm{~mm}$ diameter, respectively). The second string defines the number of anchors along the bond length (F1, F2 and F3 for 1, 2 and 3 anchors, respectively). The third string refers to the strengthening procedure (S1 and $\mathrm{S} 2$ ). Finally, the last string indicates the pre-stress level applied to the anchors (T0 and $\mathrm{T} 1$ for the case of 0 and $40 \mathrm{~N} \cdot \mathrm{m}$ torque, respectively).

The tests were performed using a servo-controlled hydraulic equipment, under displacement control with a velocity of $4 \mu \mathrm{m} / \mathrm{s}$ imposed with a displacement transducer attached to the actuator. The applied load was measured using a load cell with a static load carrying capacity of $200 \mathrm{kN}$. The relative displacement between concrete and laminate fixed to the specimen was measured with the linear variable differential transducers LVDT1 (Fig. 1).

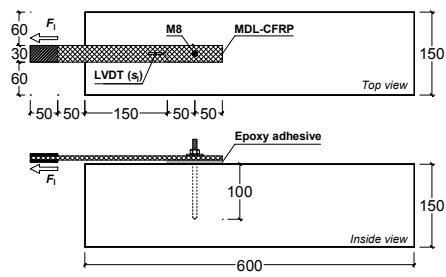

(a)

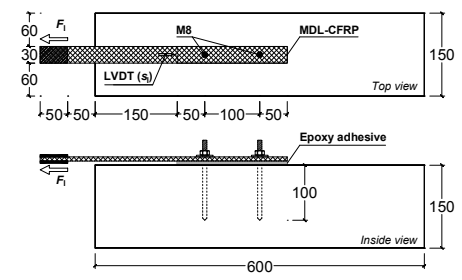

(b)

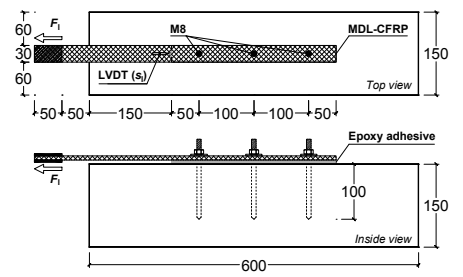

(c)

Figure 1: Specimen's geometry and pullout test configuration (units in millimetres): (a) F1 series; (b) F2 series; (c) F3 series.

\section{Material Characterization and Strengthening Procedures}

The mechanical characterization of the concrete was assessed by means of compression tests. Cylindrical concrete specimens were tested at the time of the pullout tests to evaluate the compressive strength according to the recommendations of the NP EN 12390-3:2009. An average compressive strength value of $41.54 \mathrm{MPa}$ and $56.05 \mathrm{MPa}$, with a coefficient of variation $(\mathrm{CoV})$ of $0.2 \%$ and $8.9 \%$ were obtained, respectively, for the S1 and S2 series. 
Coelho, M.; Fernandes, P.; Melo, J.; Sena-Cruz, J.M.; Varum, H.; Barros, J.; Costa, A. (2011) "Seismic retrofit of RC beam-column joints using the MF-EBR strengthening technique." Advanced Materials Research.

The steel of the longitudinal bars and stirrups has a denomination of A400 NR SD according to the NP EN 1992-1-1:2010.

The CFRP multi-directional laminate, with $2.07 \mathrm{~mm}$ thick, has $69 \%$ of fibers oriented at $0^{\circ}$ (following the applied load direction) and $31 \%$ of fibers orientated at $\pm 45^{\circ}$. The stacking sequence of this MDL-CFRP is [-45/+45/0/+45/-45]. Tensile and bearing tests of the MDL-CFRP were performed with the load direction at $0^{\circ}$ [2]. From the performed tests, a tensile strength of $1866.2 \mathrm{MPa}(\mathrm{CoV}=5.1 \%)$, a modulus of elasticity of $118.1 \mathrm{GPa}(\mathrm{CoV}=2.8 \%)$ and an ultimate strain of $1.58 \%(\mathrm{CoV}=5.1 \%)$ were obtained [2]. From the performed bearing tests, a bearing strength of $316.4 \mathrm{MPa}$ $(\mathrm{CoV}=11.8 \%)$ and $604.4 \mathrm{MPa}(\mathrm{CoV}=5.8 \%)$ were obtained for the unclamped and clamped tests, respectively [2].

The S\&P Resin 220 epoxy adhesive(C) was used to glue the laminates to the concrete. From the experimental characterization of this adhesive, a tensile strength of $33.03 \mathrm{MPa}(\mathrm{CoV}=8.52 \%)$, an ultimate strain of $0.48 \%(\mathrm{CoV}=11.80 \%)$ and a modulus of elasticity of $7.47 \mathrm{GPa}(\mathrm{CoV}=4.28 \%)$ were obtained [4]. According to the supplier, this epoxy resin has a compressive strength and a concrete/laminate bond strength of $90 \mathrm{MPa}$ and $3 \mathrm{MPa}$, respectively.

A HiltiC chemical anchors system was adopted to fix mechanically the MDL-CFRP laminate to concrete. This system is composed by resin HIT-HY 150 max, HIT-V M8 and M10 8.8 threaded anchors and DIN 9021 washers.

As previous referred, in the ambit of the present work two strengthening procedures were investigated, S1 and S2. The first step was the casting and cure of the concrete prisms. For the S1 procedure the following steps were executed: (i) holes of $10 \mathrm{~mm}$ and $12 \mathrm{~mm}$ diameter were drilled for the series M8 and M10, respectively, both with a depth of $100 \mathrm{~mm}$; (ii) a rough concrete surface was created by using a rotary hammer with a needle adapter; (iii) the holes and the final glued surface were cleaned by using compressed-air and a steel brush; (iv) the holes were filled with the chemical adhesive, and the fasteners were inserted up to a depth of $100 \mathrm{~mm}$; (v) the position of the fasteners was marked with a transparent acrylic strip and, then, the holes in the laminates were drilled using this acrylic strip; (vi) the epoxy adhesive was applied on the treated area of the concrete surface and on the previously cleaned laminate surface that will be in contact with the concrete; (vii) the laminate was placed on the concrete surface by pressing it against to concrete in order to create an uniform thickness of 1 to $2 \mathrm{~mm}$ of adhesive layer; (viii) the adhesive in excess was removed. The S2 procedure was composed by the following steps: (ii), (iii - the surface part), (vi), (vii), (viii), (i), (iii - the holes part) and (iv). From a practical point of view, the holes in the MDL-CFRP should be done after it has been glued to the concrete. This strategy was followed in S2 procedure.

The tests were performed, at least, 7 days after the application of the adhesive to glue the laminate to concrete. For the T1 series, the pre-stress was applied in two phases: one day before the test, a torque moment of $40 \mathrm{~N} \cdot \mathrm{m}$ was applied to the anchors; in the day of the test, the same torque level was again adjusted. 
Coelho, M.; Fernandes, P.; Melo, J.; Sena-Cruz, J.M.; Varum, H.; Barros, J.; Costa, A. (2011) "Seismic retrofit of RC beam-column joints using the MF-EBR strengthening technique." Advanced Materials Research.

\section{Results}

Table 1 includes the main results obtained for all the series in terms of maximum pullout force $\left(F_{\max }\right)$, loaded end slip $\left(s_{1}\right)$ and failure modes. Figure 2 depicts typical relationships of the pullout force versus loaded end slip.

Table 1: Main results obtained (average values).

\begin{tabular}{|c|c|c|c|}
\hline Series & $F_{\max }[\mathrm{kN}]$ & $s_{1}[\mathrm{~mm}]$ & Failure mode \\
\hline M8F3S1T0 & $34.14(12.18 \%)$ & $3.55(16.03 \%)$ & IC+ID+BF(3)* \\
\hline M8F3S2T0 & $32.89(8.33 \%)$ & $5.28(25.81 \%)$ & IC+ID+BF(3)* \\
\hline M10F3S1T0 & $48.99(5.77 \%)$ & $3.67(24.49 \%)$ & IC+E(1)*; IC+ID+E(1)* \\
\hline M10F3S2T0 & $48.31(7.83 \%)$ & $4.66(14.22 \%)$ & IC+ID+BF(3)* \\
\hline M8F1S2T0 & $15.00(13.27 \%)$ & $0.36(20.88 \%)$ & IC+ID+BF(3)* \\
\hline M8F1S2T1 & $20.95(3.56 \%)$ & $0.47(19.30 \%)$ & IL+BF(3)* \\
\hline M8F2S2T0 & $23.48(15.28 \%)$ & $0.76(33.44 \%)$ & IC+ID+BF(3)* \\
\hline M8F2S2T1 & $37.01(6.03 \%)$ & $1.07(14.05 \%)$ & IC+ID+BF(1)*; D+E(2)* \\
\hline M8F3S2T1 & $48.35(6.66 \%)$ & $1.59(4.18 \%)$ & ID+BF(3)* \\
\hline M10F1S2T0 & $23.12(2.66 \%)$ & $0.45(24.94 \%)$ & IC+D+BF(2)*; IL+BF(1)* \\
\hline M10F1S2T1 & $27.32(3.62 \%)$ & $0.40(41.88 \%)$ & IL+BF(3)* \\
\hline M10F2S2T0 & $28.29(14.85 \%)$ & $0.82(10.68 \%)$ & IC+ID+BF(3)* \\
\hline M10F2S2T1 & $40.38(9.04 \%)$ & $0.93(10.73 \%)$ & IL+ID+BF(3)* \\
\hline M10F3S2T1 & $57.76(2.81 \%)$ & $1.29(12.76 \%)$ & ID+BF(3)* \\
\hline
\end{tabular}

Notes: the values between parentheses are the corresponding coefficients of variation; failure modes: IC=Debonding at the concrete/adhesive interface; $\mathrm{IL}=$ Debonding at the laminate/adhesive interface; $\mathrm{ID}=\mathrm{MDL}-\mathrm{CFRP}$ inter-delamination; $\mathrm{BF}=\mathrm{Bearing}$ failure; *the value between parenthesis is the number of specimens with that type of failure mode.
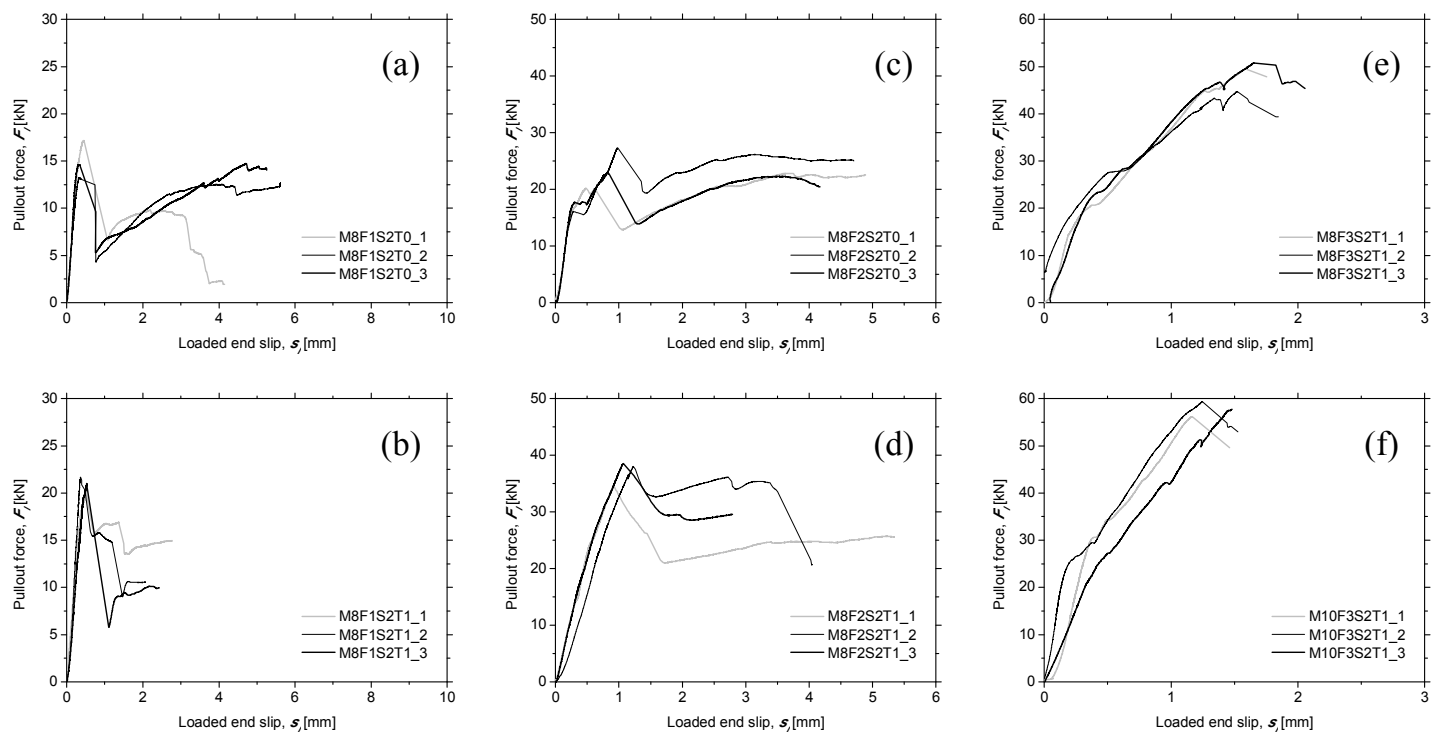

Figure 2: Pullout force versus loaded end slip for the series: (a) M8F1S2T0; (b) M8F1S2T1; (c) M8F2S2T0; (d) M8F2S2T1; (e) M8F3S2T1; (f) M10F3S2T1.

When series $\mathrm{S} 1$ and $\mathrm{S} 2$ are compared in terms of maximum load, a marginal difference of $3.7 \%$ and $1.4 \%$ were obtained for the M8 and M10 anchors, 
respectively. In addition, similar failure modes were observed for practically all of the specimens analysed. These failure modes include a mix of three components: debonding at the concrete/adhesive and laminate/adhesive interfaces, and bearing failure at the laminate.

As expected, the maximum pullout force increases with the number of anchors. This effect is, however, more evident for the T1 series where the pre-stress is applied to the anchors. In fact, when the $\mathrm{F} 2$ and $\mathrm{F} 1$ series are compared, the variation of $F_{\max }$ for (M8F2T0, M8F1T0) and (M8F2T1, M8F1T1) were 56.5\% and 76.6\%, respectively, whereas for the case of (M10F2T0, M10F1T0) and (M10F2T0, M10F1T0) were $22.4 \%$ and $47.8 \%$, respectively. This performance may be justified by the fact that the confinement in the vicinity of the anchors, provided by the pre-stress, allowed superior frictional angle at the concrete/adhesive and laminate/adhesive interfaces.

When the effect of the diameter of the anchors is analysed, i.e. M8 and M10 series are compared, it is observed that $F_{\max }$ is higher in M10. This behaviour is justified by the failure mode obtained. In fact, for the majority of the series, bearing failure occurred at the laminate in the vicinity of the anchors. Since the bearing failure of the M10 involved a superior contact area, a higher strength was expected. Other interesting observation is the fact that the increment in terms of $F_{\max }$ for the pre-stressed series (T1) was higher for the case of M8 instead of M10. In fact for M8F1S2T1 and M8F2S2T1 series the increase due to the application of the pre-stress was $39.7 \%$ and $57.6 \%$, respectively, whereas for the case of M10F1S2T1 and M10F2S2T1 series was $18.2 \%$ and $42.7 \%$, respectively. Since the same level of pre-stress was applied for M8 and M10, this behaviour was expected.

For the F1 series the pullout force versus loaded end slip $\left(F_{1}-S_{1}\right)$ relationships, up to the peak load, are very similar (see Fig. $2 \mathrm{a}$ and b). In fact, an almost linear trend for both pre-stressed and non pre-stressed series was observed. However, as expected, the T1 series presented higher stiffness and strength. The peak load coincides with the full debonding of the concrete/adhesive interface.

The presence of the two anchors (F2 series) is clearly identified by the "two peaks" in the up to peak load (see Fig. 2c). This behaviour was no longer observed in the series with pre-stressed anchors (see Fig. 2d). Indeed the stress state provided by the pre-stress led to a smoother response.

The relationships $F_{1}-S_{1}$ of F3 series (see Fig. 2e and f) for the case of M8 and M10 are quite similar up to the peak load. However, higher strength can be observed for the case of M10.

Debonding at the concrete/adhesive (IC) and laminate/adhesive (IL) interfaces, MDL-CFRP inter-delamination (ID) and bearing failure at the laminate (BF) were the observed failure modes. The IC $+\mathrm{ID}+\mathrm{BF}$ is the most observed failure mode. The IC is a failure mode currently observed with the EBR strengthening technique, whereas BF failure mode is observed in the MF-FRP one. Since the MF-EBR is a hybrid strengthening technique, a "hybrid" failure mode is expected. 
Coelho, M.; Fernandes, P.; Melo, J.; Sena-Cruz, J.M.; Varum, H.; Barros, J.; Costa, A. (2011) "Seismic retrofit of RC beam-column joints using the MF-EBR strengthening technique." Advanced Materials Research.

\section{Conclusions}

In the present work, a description was given about the main aspects of an experimental program carried out to assess the bond behavior of multi-directional CFRP laminates that are simultaneously anchored and bonded to concrete elements. In this experimental program, by executing pullout tests, the influence of the diameter (M8 and M10) and number of anchors (F1, F2 and F3), the applied pre-stress level on them (T0 and $\mathrm{T} 1)$ and the strengthening procedure (S1 and S2) were studied.

Both strengthening procedures yielded to similar results. This aspect should be highlighted since from practical point of view the S2 procedure is significantly simpler to be applied.

As expected, the maximum pullout force, $F_{\max }$, increased with the number and diameter of the anchors. Applying a pre-stress due to a torque moment of 40 N.mm, the $F_{\max }$ has increased in about $57 \%$, when compared with similar solutions without pre-stress.

The pullout force versus slip responses were non-linear up to peak, mainly for the series F2 and F3. For the case of pre-stressed anchors a more "uniform" response was obtained. Mixed failure modes have occurred, by debonding at the interfaces concrete/adhesive and adhesive/concrete, bearing at the MDL-CFRP and inter-delamination of the laminate.

\section{Acknowledgements}

This work was supported by FEDER funds through the Operational Program for Competitiveness Factors - COMPETE and National Funds through FCT - Portuguese Foundation for Science and Technology under the project PTDC/ECM/74337/2006. The authors acknowledge the materials generously supplied by Hilti Portugal Productos e Serviços Lda., S\&P Clever Reinforcement Ibérica Lda. and SECIL.

\section{References}

[1] L. Bank, D. Arora: Composite Structures, Vol. 79 (2007), p. 180-191.

[2] J.M. Sena-Cruz, J.A.O. Barros, M.R.F. Coelho: Adv. Mater. Res. Vols.133-134 (2010), p. 917-922.

[3] J.M. Sena-Cruz, J.A.O. Barros, M.R.F. Coelho, L. Silva, in: CDCC'2011 - Fourth International Conference on Durability \& Sustainability of Fibre Reinforced Polymer Composites for Construction and Rehabilitation, edited by B. Benmokrane, E. El-Salakawy, E. Ahmed (2011) , p. 253-261.

[4] E. Bonaldo: Composite materials and discrete steel fibers for the strengthening of thin concrete structures. $\mathrm{PhD}$ thesis, Dept. of Civil Engineering, Univ. of Minho, (2008), 404 pp. $<$ http://hdl.handle.net/1822/8842> 